\title{
29-Silicon NMR evidence for the improved chromatographic siloxane bond stability of bulky alkylsilane ligands on a silica surface
}

Citation for published version (APA):

Scholten, A. B., Haan, de, J. W., Claessens, H. A., Ven, van de, L. J. M., \& Cramers, C. A. (1994). 29-Silicon NMR evidence for the improved chromatographic siloxane bond stability of bulky alkylsilane ligands on a silica surface. Journal of Chromatography, A, 688(1-2), 25-29. https://doi.org/10.1016/0021-9673\%2894\%2900928-7, https://doi.org/10.1016/0021-9673(94)00928-7

DOI:

10.1016/0021-9673\%2894\%2900928-7

10.1016/0021-9673(94)00928-7

Document status and date:

Published: 01/01/1994

Document Version:

Publisher's PDF, also known as Version of Record (includes final page, issue and volume numbers)

Please check the document version of this publication:

- A submitted manuscript is the version of the article upon submission and before peer-review. There can be important differences between the submitted version and the official published version of record. People interested in the research are advised to contact the author for the final version of the publication, or visit the $\mathrm{DOI}$ to the publisher's website.

- The final author version and the galley proof are versions of the publication after peer review.

- The final published version features the final layout of the paper including the volume, issue and page numbers.

Link to publication

\footnotetext{
General rights

- You may freely distribute the URL identifying the publication in the public portal. follow below link for the End User Agreement:

www.tue.nl/taverne

\section{Take down policy}

If you believe that this document breaches copyright please contact us at:

openaccess@tue.nl

providing details and we will investigate your claim.
}

Copyright and moral rights for the publications made accessible in the public portal are retained by the authors and/or other copyright owners and it is a condition of accessing publications that users recognise and abide by the legal requirements associated with these rights.

- Users may download and print one copy of any publication from the public portal for the purpose of private study or research.

- You may not further distribute the material or use it for any profit-making activity or commercial gain

If the publication is distributed under the terms of Article 25fa of the Dutch Copyright Act, indicated by the "Taverne" license above, please 


\title{
29-Silicon NMR evidence for the improved chromatographic siloxane bond stability of bulky alkylsilane ligands on a silica surface
}

\author{
Alex B. Scholten*, Jan W. de Haan, Henk A. Claessens, Leo J.M. van de Ven, \\ Carel A. Cramers \\ Eindhoven University of Technology, Laboratory of Instrumental Analysis. P.O. Box 513, 5600 MB Eindhoven, Netherlands
}

First received 5 August 1994; revised manuscript received 28 September 1994

\begin{abstract}
A stable bond stationary phase for reversed-phase high-performance liquid chromatography, with a diisobutyl- $n$ octadecylsilane derivatized surface, was studied using ${ }^{20} \mathrm{Si}$ cross-polarization magic angle spinning (CP MAS) NMR. Fumed silica surfaces (Aerosil), trimethylsilylated to different extents, were used to illustrate the effect of ligand surface loading on the hydrogen bonding contribution to the ligand silane CP MAS NMR signal. Spectral comparison of the diisobutyl- $n$-octadecylsilane derivatized silica with the conventional dimethyl- $n$-octadecylsilane derivatized silica revealed significantly decreased hydrogen bonding of residual silanols to the ligand siloxane bond in the diisobutyl-n-octadecyl phase. This illustrates the increased steric protection of the ligand siloxane bond by the bulky alkyl substituents, which is assumed to be the reason for the improved hydrolytic stability at low pH of this phase.
\end{abstract}

\section{Introduction}

In many applications of reversed-phase highperformance liquid chromatography (RP. HPLC), stationary phase degradation is a major drawback when using alkylsilane-modified silica surfaces because of the hydrolytic instability of siloxane bonds. The lifetime of one column packing may not even be sufficient to perform adequate experimental designs for optimizing separation efficiencies [1]. Consequently, much research was done to identify the most important factors involved in phase deterioration and to design new stationary phases with improved

* Corresponding author. stability. Kirkland et al. proposed that bulky substituents in the silanizing reagent (for example, diisobutyl- $n$-octadecylsilane instead of dimethyl- $n$-octadecylsilane) would result in a more efficient steric protection of the silica surface and, in particular, the ligand siloxane bond [2]. These so-called stable bond phases indeed exhibit superior hydrolytic stability at low $\mathrm{pH}[3,4]$. However, the improved steric protection was not observed as such; it was postulated using the increased chromatographic stability as a criterion.

Of the physicochemical methods used to investigate chromatographic silica surfaces, solidstate NMR has proven to be a powerful tool that enables identification of different chemical sur- 
face structures. The goal of much research has been to relate NMR characteristics of the detected chemical surface species to the observed chromatographic behaviour of silica surfaces [511]. In this paper we present ${ }^{29} \mathrm{Si}$ cross-polarization magic angle spinning (CP MAS) NMR evidence for a decreased contribution of hydrogen bonding groups to the ligand silane signal in diisobutyl- $n$-octadecylsilane-modified silica gel compared to the dimethyl- $n$-octadecylsilane analoguc. This inhibition of hydrogen bonding is brought about by steric protection of the ligand siloxane bond by the bulky isobutyl substituents.

\section{Experimental}

The two Zorbax octadecyl phases used in this study were obtained from Rockland Technologies (Newport, DE, USA). One is a dimethyl- $n$-octadecylsilane derivatized silica, $\mathrm{Rx}$ $\mathrm{C}_{18}$, with a carbon content of $12.25 \%$ (ligand density $=3.37 \mu \mathrm{mol} / \mathrm{m}^{2}$ ), the other is a diisobutyl- $n$-octadecylsilane derivatized silica, SB-C $\mathrm{C}_{18}$, with a carbon content of $9.85 \%$ (ligand density $=2.00 \mu \mathrm{mol} / \mathrm{m}^{2}$ ). Both phases were prepared from the same silica substrate: Rx-Sil, with a surface area of $180 \mathrm{~m}^{2} / \mathrm{g}$, a particle size of 5.4 $\mu \mathrm{m}$, an average pore diameter of $80 \AA$ and a pore volume of $0.45 \mathrm{ml} / \mathrm{g}$ (as reported by the manufacturer). In addition, four batches of a fumed silica (Aerosil A-200, Degussa, Frankfurt, Germany), trimethylsilylated to different degrees as described earlier [12], were also studied by ${ }^{29} \mathrm{Si}$ CP MAS NMR. All silicas were dried in vacuum for $\gamma$ h at $110^{\circ} \mathrm{C}$.

${ }^{29}$ Si CP MAS NMR spectra were obtained on a Bruker MSL-400 NMR spectrometer (Bruker, Rheinstetten, Germany) at a Larmor frequency of $79.6 \mathrm{MHz}$. Approximately $250 \mathrm{mg}$ siliceous material was filled into zirconia rotors $(7 \mathrm{~mm})$ of the Bruker double bearing type. The magic angle spinning frequency was $2 \mathrm{kHz}$, using air as the driving gas. Contact time variation revealed that $6 \mathrm{~ms}$ was an appropriate setting for comparing the spectra of the Aerosil samples. The contact time for the Zorbax phases was set to $3 \mathrm{~ms}$. The acquisition time was $10 \mathrm{~ms}$ and the pulse delay time was $4 \mathrm{~s}$. A total of 3000 free induction decays were added in $1 \mathrm{~K}$ data points and zero filled to $8 \mathrm{~K}$. A line broadening of $20 \mathrm{~Hz}$ was applied prior to Fourier transformation. NMR chemical shifts are referenced to liquid tetramethylsilane, using $\mathrm{Q}_{8} \mathrm{M}_{8}$ (the trimethylsilylester of cubic octameric silicate) as an external reference.

\section{Results and discussion}

Fig. 1 displays the ${ }^{29} \mathrm{Si}$ CP MAS NMR spectra of the Aerosil samples in the silane ligand region for four different degrees of trimethylsilylation. Clearly, the chemical shift of the maximum of the ligand signal decrcases with increasing surface coverage. Also, the asymmetry of the signals due to a shoulder at the left of the peak maximum is evident. Very recently, Haukka and Root [13] reported that a similar shoulder is also evident in the earlier pioneering work on silylated silicas $[14,15]$, but that it never was commented on. They proposed to assign this signal to trimethylsilyl groups produced by the reaction of hexamethyldisilazane (HMDS) with a terminal silanol group of which the oxygen atom is involved in hydrogen bonding and the proton is uncoordinated. Many other authors postulate this type of silanol functionality to be more acidic and thus more reactive towards silanizing reagents such as HMDS [13]. After silylation, the oxygen atom in the ligand siloxane bond can still be involved in hydrogen bonding to the neighbouring silanol functionality, leading to a magnetic deshielding of the silane silicon nucleus (downfield shift of the NMR signal). A rather convincing argument for Haukka and Root's assignment is the observation that the shoulder is less pronounced, or even not present at all, after silylation of high temperature (up to $820^{\circ} \mathrm{C}$ ) pretreated silica substrates. This high temperature curing causes the surface silanols to form siloxane bonds with neighbouring silanols. The resulting lower silanol surface concentration decreases the possibilities of hydrogen bonding of residual silanols to the ligand siloxane bonds 


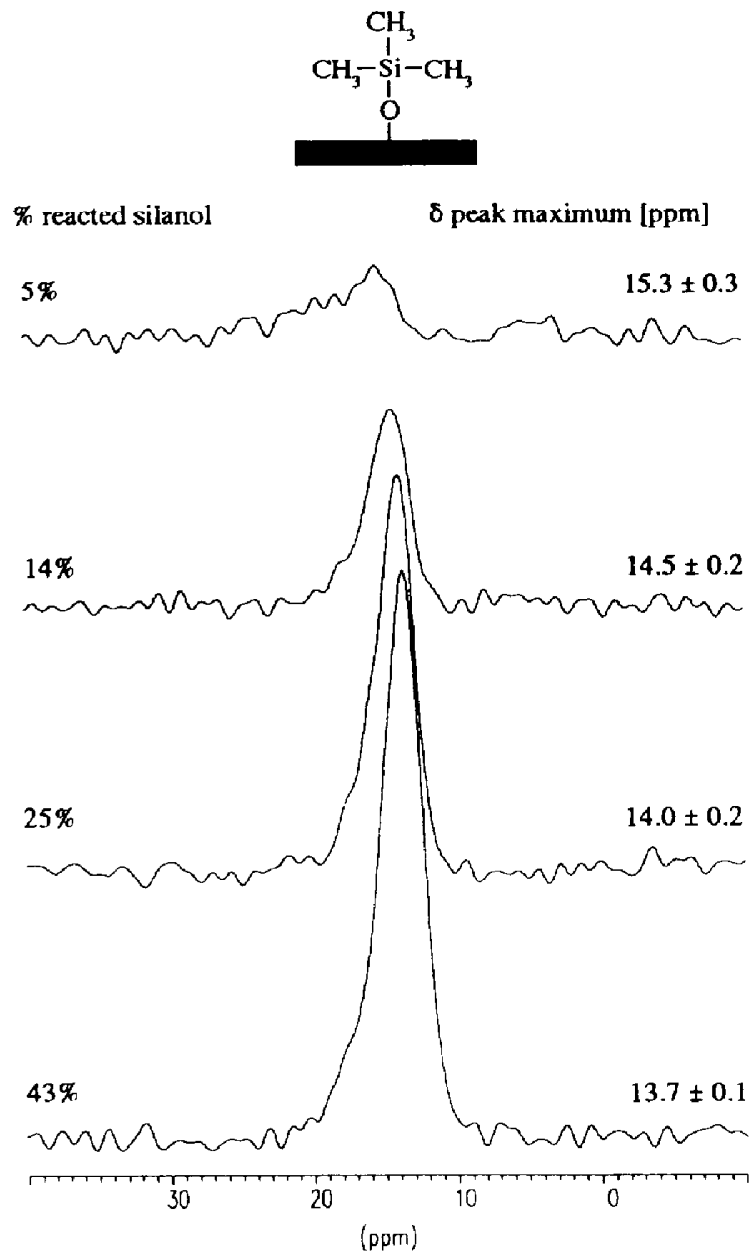

Fig. 1. ${ }^{24} \mathrm{Si}$ CP MAS NMR spectra of Aerosil A-200 with trimethylsiloxane surface coverages and chemical shifts of the peak maxima ( \pm maximum error) as indicated. All spectra are on the same intensity scale.

after silylation. Now, Fig. 1 illustrates that in our case, where the silanol surface concentration is decreased by means of trimethylsilylation, the relative contribution of the hydrogen bonding residual silanols to the ligand siloxane signal is decreased because the signal maximum is shifted to lower ppm values.

Fig. 2 displays the ${ }^{29} \mathrm{Si}$ CP MAS NMR spectra of the two Zorbax $\mathrm{C}_{18}$ phases. Before considering the asymmetry of the silane ligand NMR signals, it should be noted that the peak maximum of the SB-C $\mathrm{C}_{18}$ ligand signal is shifted $2 \mathrm{ppm}$ upfield from the maximum of the $\mathrm{Rx}-\mathrm{C}_{18}$ ligand

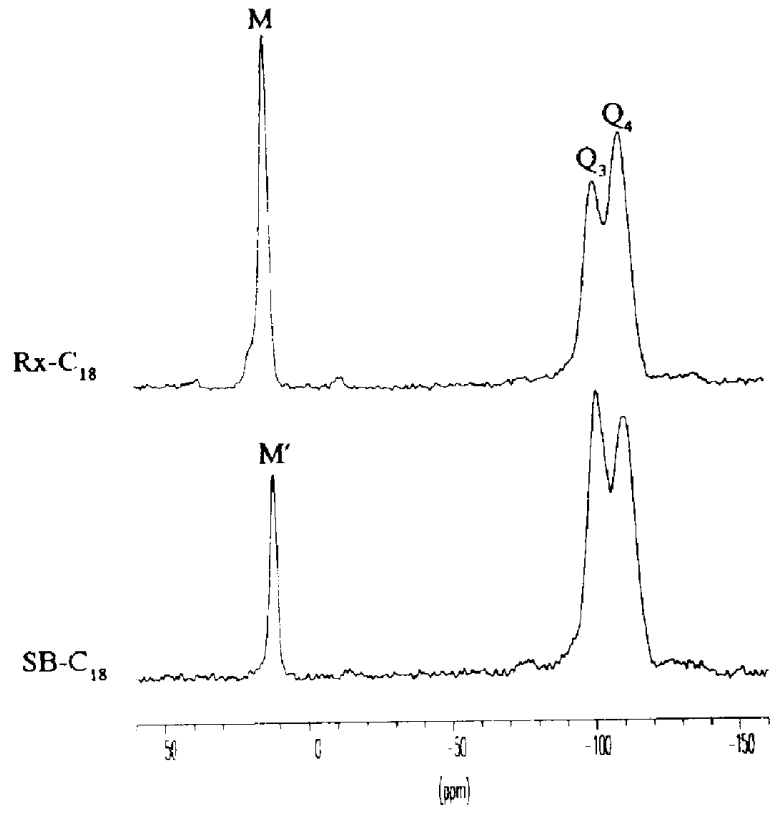

Fig. 2. ${ }^{29}$ Si CP MAS NMR spectra of the Zorbax octadecyl RP-HPLC phases. Both spectra are on the same intensity scale. $\quad M=$ dimethyl- $n$-octadecylsiloxane, $\mathbf{M}^{\prime}=$ diisobutyl- $n$ octadecylsiloxane, $Q_{3}=$ single silanol, $Q_{4}=$ siloxane.

signal. This is due to the $\beta$ effect on ${ }^{29} \mathrm{Si}$ upon substitution of two hydrogen atoms for two isopropyl groups. This chemical shift difference is, however, irrelevant in the following discussion. The attention is focused on the degree of asymmetry of both signals. It appears that the shoulder in the $\mathrm{SB}-\mathrm{C}_{18}$ spectrum is much less pronounced, indicating that the ligand siloxane bond is involved in hydrogen bonding only to a small extent. In the $\mathrm{Rx}-\mathrm{C}_{18}$ spectrum on the other hand, the shoulder is clearly discernible. It should be noted that the surface coverage by the diisobutyl- $n$-octadecylsilane ligands is much lower than that of the dimethyl-n-octadecylsilane ligands ( $26 \%$ vs. $44 \%$ of reacted silanols, assuming a generally accepted initial silanol surface concentration of $7.6 \mu \mathrm{mol} / \mathrm{m}^{2}$ on a fully hydroxylated silica surface: Kiselev-Zhuravlev constant $=4.6 \mathrm{~nm}^{-2}[16]$ ). Bearing in mind the result of the trimethylsilylated Aerosil surfaces, where increasing surface coverage is accompanied by a decreasing hydrogen bonding contribution to the NMR signal, the slight asymmetry 


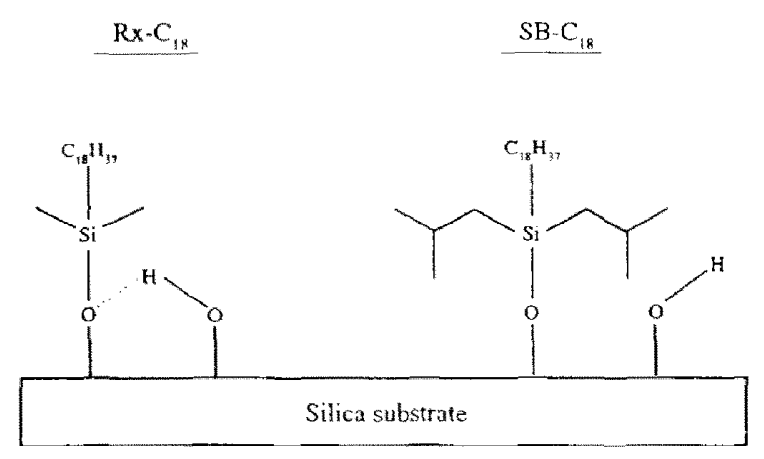

Fig. 3. Schematic drawing of the dimethyl-n-octadecylsilyl and the diisobutyl-n-octadecylsiloxane surface structures, illustrating the increased steric protection of the ligand siloxane bond by the bulky side groups in the latter.

of the SB-C 18 ligand NMR signal strongly suggests the superior steric shielding properties of the isobutyl groups. This is schematically illustrated in Fig. 3.

In an attempt to roughly quantify this hydrogen bonding contribution, the spectra of the two $n$-octadecyl phases were deconvoluted using the Bruker Linesim software. As is known from theory, solid-state NMR signals generally have Gaussian line shapes, thus Gaussian functions were used in the spectral deconvolution. A total of three Gaussian line shapes appeared necessary to accurately fit the experimental traces. Fig. 4 shows the results of these simulations and Table
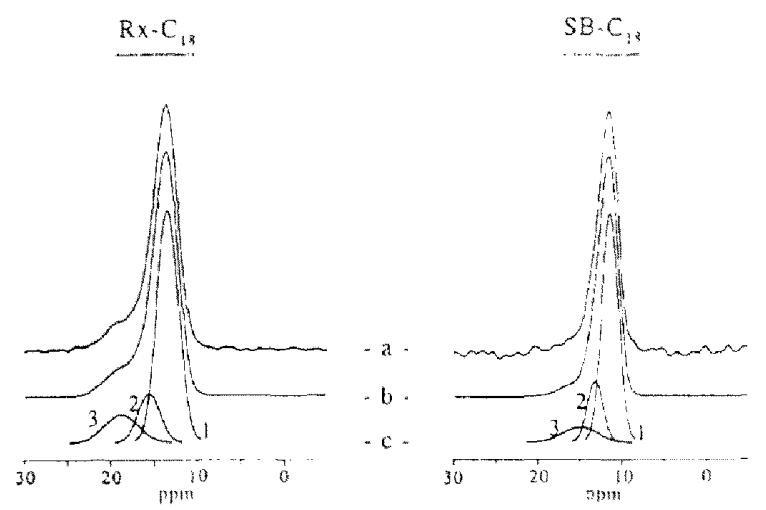

Fig. 4. Experimental (a), simulated (b) and deconvoluted (c) traces of the ligand siloxane signals of the ${ }^{29} \mathrm{Si}$ CP MAS NMR spectra of the $R x-C_{1 *}$ phase (left) and the $S B-C_{1 *}$ phase (right). The numbers next to the individual Gaussians correspond to the peak numbers in Table 1.
1 summarizes the relevant numerical data. The main peak ( $\mathrm{nr} .1$ ) in the simulated traces represents silane silicon atoms attached to former singlc silanol $\left(Q_{3}\right)$ groups, of which the siloxane bond to the silica surface is not involved in hydrogen bonding. The second peak (nr. 2), 2 ppm downfield from the main signal, has an intensity about 4 to 5 times smaller than the main peak. We assign this signal to the silane species after reaction with silanediol $\left(\mathrm{Q}_{2}\right)$ groups as the ratio $1: 5$ reflects the $Q_{2}: Q_{3}$ ratio of the native silica gel. The third Gaussian (nr. 3) is mainly responsible for the asymmetry of the total ligand signal. In line with Haukka and Root's results, this peak is assigned to the ligand siloxane bonds involved in hydrogen bonding.

From Table 1 several arguments can be deduced to sustain the supposed increased shielding of the ligand siloxane bond in the $S B-C_{18}$ phase. First, peak number 3 has a greater downfield shift compared to the main peak (number 1) 1) in the $\mathrm{Rx}-\mathrm{C}_{18}$ phase, indicating a stronger hydrogen bond. Second, this peak has a higher intensity and a larger relative area. Furthermore, the main peak (nr. 1) at $11.5 \mathrm{ppm}$ in the

Table 1

Relevant data of the three Gaussian peak shapes used to simulate the experimental ligand silane ${ }^{29} \mathrm{Si}$ CP MAS NMR signal of the $\mathrm{Rx}-\mathrm{C}_{18}$ and the SB-C $\mathrm{C}_{78}$ phase

\begin{tabular}{|c|c|c|c|c|}
\hline $\begin{array}{l}\text { Phase. } \\
\text { peak } \\
\text { nr." }\end{array}$ & $\begin{array}{l}\delta \\
\delta \\
(\mathrm{ppm})\end{array}$ & Intensity ${ }^{\mathrm{h}}$ & $\begin{array}{l}\text { Width } \\
(\mathrm{Hz})\end{array}$ & $\begin{array}{l}\text { Relative } \\
\text { area }(\%)\end{array}$ \\
\hline \multicolumn{5}{|l|}{$\mathrm{Rx}-\mathrm{C}_{18}$} \\
\hline 1 & 13.4 & $95.0(0.7)$ & $236(4)$ & $71.6(0.4)$ \\
\hline 2 & 15.7 & $19.6(1.0)$ & $242(7)$ & $15.2(0.6)$ \\
\hline 3 & 18.8 & $11.3(0.5)$ & $364(21)$ & $13.2(0.7)$ \\
\hline \multicolumn{5}{|l|}{$S B-C_{3 k}$} \\
\hline 1 & 11.5 & $95.6(0.6)$ & $182(3)$ & $72.2(0.4)$ \\
\hline 2 & 13.2 & $25.2(1.1)$ & $173(7)$ & $18.1(0.7)$ \\
\hline 3 & 15.1 & $6.2(0.3)$ & $378(22)$ & $9.7(0.5)$ \\
\hline
\end{tabular}

Values in parentheses are \pm estimated maximum errors, determined by manual distortion of the separate parameters to the point where visual inspection clearly indicated a lack of fit.

${ }^{*}$ For assignments, see text.

"Maximum in the experimental trace $=100$. 
simulated traces of the $\mathrm{SB}-\mathrm{C}_{18}$ spectrum has a considerably smaller width than the corresponding peak at $13.4 \mathrm{ppm}$ in the $\mathrm{Rx}-\mathrm{C}_{18}$ simulated trace. The same is true for peak number 2 . This points to a decreased site dispersion for the silane silicon atom caused by the large cloud of isobutyl groups surrounding the silane silicon atom, which is thus effectively shielded from interactions that would contribute to its site dispersion.

Together, these observations strongly suggest the increased steric protection of the ligand siloxane bond in the diisobutyl- $n$-octadecylsilane derivatized surface, especially if the surface loading effect is taken into account too.

\section{Conclusions}

It is proved, using ${ }^{24} \mathrm{Si} \mathrm{CP}$ MAS NMR, that isobutyl side groups of ligand silane chains of a silica based RP-HPLC phase provide a significantly increased steric protection of the ligand siloxane bond compared to their methyl analogues. Hydrogen bonding of residual silanols to the ligand siloxane oxygen atoms is shown to occur much less in the diisobutyl-n-octadecylsilane derivatized silica. It is likely that this also explains the increased chromatographic stability at low $\mathrm{pH}$ of these stable bond phases, as the siloxane bond is protected from contact with aggressive, hydrolyzing eluents. It has very recently been demonstrated, however, that at high $\mathrm{pH}$ stable bond phases degrade more rapidly [17]. At high $\mathrm{pH}$, dissolution of the silica substrate is the major cause of $n$-octadecylsilane stationary phase degradation [18]. The lower surface coverage of diisobutyl- $n$-octadecylsilane phase compared to the dimethyl- $n$-octadecylsilane phase apparently provides a less effective shielding of the underlying silica substrate. Therefore, the term "stable bond" phase refers to the increased stability of the ligand-tosilica siloxane bond.

\section{Acknowledgment}

Dr. J.J. Kirkland from Rockland Technologies Inc. is gratefully acknowledged for the donation of the Zorbax phases.

\section{References}

[1] B. Bourguignon and D.L. Massart, Anal. Chim. Acta, 282 (1993) 33.

[2] J.J. Kirkland, J.L. Glajch and R.D. Farlee, Anal. Chem., 61 (1989) 2.

[3] J.J. Kirkland, C.H. Dilks, Jr. and J.E. Henderson, LC-GC Int., 6 (1993) 436.

[4] A. Houbenová, H.A. Claessens, J.W. de Haan, C.A. Cramers and K. Stulik, J. Liquid Chromatogr., 17 (1994) 46.

[5] K. Albert, R. Brindle, J. Schmid, B. Buszewski and E. Bayer, Chromatographia, 38 (1994) 283

[6] K. Albert and E. Bayer, J. Chromatogr., 544 (1991) 370 .

[7| R.K. Gilpin and M.E. Gangoda, J. Magn. Reson., 64 (1985) 408 .

[8] D.W. Sindorf and G.E. Maciel, J. Am. Chem. Soc., 105 (1983) 1848.

[9] D.M. Bliesner and K.B. Sentell, Anal, Chem., 65 (1993) 1819.

[10] M.3.J. Hetem, J.W. de Haan, H.A. Claessens, L.J.M. van de Ven, C.A. Cramers and J.N. Kinkel, Anal. Chem., 62 (1990) 2288.

[11] M. Hanson, K.K. Unger, J.S. Schmid, K. Albert and E. Bayer, Anal. Chem., 65 (1993) 2249.

[12] A.B. Scholten, H.-G. Janssen, J.W. de Haan and C.A. Cramers, J. High Resolut. Chromatogr., 17 (1994) 77.

[13] S. Haukka and A. Root, I. Phys. Chem., 98 (1994) 1695 , and references therein.

[14] D.W. Sindorf and G.E. Maciel, J. Am. Chem. Soc., 103 (1981) 4263 .

[15] D.W. Sindorf and G.E. Maciel, J. Phys. Chem., 86 (1982) 5208.

[16] L. T. Zhuravlev, Colloids Surf. A, 74 (1993) 71.

[17] J.J. Kirkland, M.A. van Straten and H.A. Claessens, $J$. Chromatogr, in press.

[18] A.B. Scholten, J.W. de Haan, L.J.M. van de Ven, H.A. Claessens and C.A. Cramers, Anal. Chem., in press. 